\title{
Seeing is believing
}

\author{
Suk Jung Choo, MD
}

\footnotetext{
From the Department of Thoracic and Cardiovascular Surgery, Asan Medical Center, Ulsan University School of Medicine, Seoul, Republic of Korea.

Disclosures: Author has nothing to disclose with regard to commercial support.

Received for publication Feb 21, 2017; accepted for publication March 6, 2017; available ahead of print April 4, 2017.

Address for reprints: Suk Jung Choo, MD, Department of Thoracic and Cardiovascular Surgery, Asan Medical Center, Ulsan University School of Medicine, 388-1 Poongnap-dong Songpa-gu, Seoul, 138-736 Republic of Korea (E-mail: sjchoo@amc.seoul.kr).

J Thorac Cardiovasc Surg 2017;154:30-1

$0022-5223 / \$ 36.00$

Copyright $(c) 2017$ by The American Association for Thoracic Surgery

http://dx.doi.org/10.1016/j.jtcvs.2017.03.014
}

Miyahara and colleagues ${ }^{1}$ introduce endoscopic valve assessment as a direct method to visually assess the repair outcomes of valve-sparing root replacement during cardioplegic arrest. An 8.5 Fr flexible ureteroscope is passed through the right superior pulmonary vein and positioned in the left ventricular cavity to visualize the aortic valve for any leakage under pressures up to $250 \mathrm{~mm} \mathrm{Hg}$. The authors previously demonstrated proof of concept of this technique in a case report ${ }^{2}$ and proceeded to use it in a subsequent series of 36 patients who form the basis of the present study. ${ }^{1}$

Postrepair valve function regardless of technique must eventually pass the test of intraoperative transesophageal echocardiography (TEE) after bypass weaning. If the valve performance is unsatisfactory, as evidenced by significant aortic regurgitation, the surgeon must choose between repeating cardiopulmonary bypass for yet another repair attempt in the face of a third pump run possibility or playing it safe and accepting defeat in replacing the valve. During surgery, it is that period before the distal graft anastomosis is completed that the desire to know the results before the TEE outcome is greatest. Direct valve visualization after pouring saline into the root allows a surgeon to check if the valve looks nice while holding water. However, this has extremely low correlation with function. Alternately, the distal stump may be clamped and the root pressurized with cardioplegic solution to see if the aortic root can maintain pressure without causing significant left ventricular distension or excessive vent return. In either case, the correlation with intraoperative TEE is often only partially reliable. Other investigators have attempted videoscopic assessment of the valve repair during cardioplegia, ${ }^{3-6}$ but were only able to visualize the aortic valve from the aortic side distally to the valve. Although a surgeon may view the leaflet coaptation status under pressure with this approach, no detailed information may be obtained regarding the quality or the quantity of the leak. The current direct scope-assisted visualization allows more accurate assessment of regurgitation under similar conditions

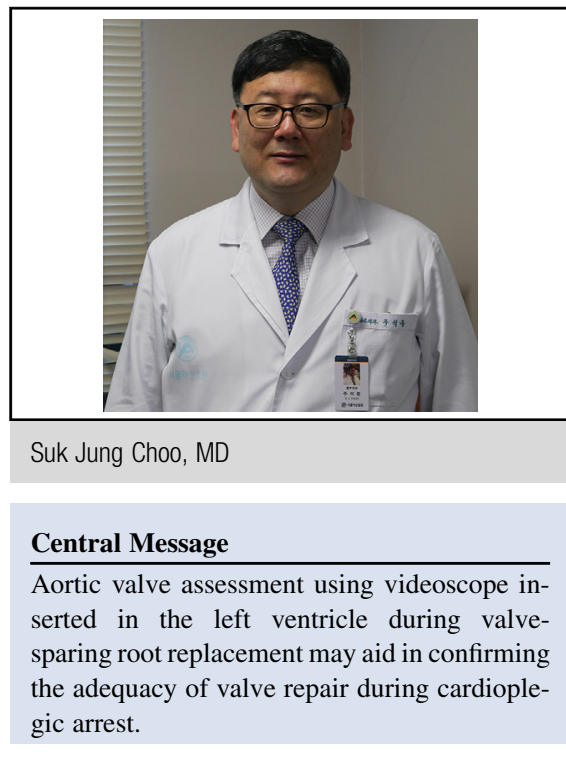

See Article page 24.

but from the ventricle side. This has some unique advantages because various degrees of residual leaks can be observed as well as their direction and orientation. This is highlighted by the fact that root pressurization alone does not necessarily ensure absence of regurgitation or its nature. Furthermore, the siphoning effect of coronary runoffs after coronary button reattachment somewhat confounds judgment of valve competence based on root pressurization. Therefore, the current lack of any established method to assess aortic regurgitation after valve repair during cardiac arrest makes this an important addition to the currently available limited measures. In the present study, ${ }^{1}$ the valve is tested under higher-than-physiologic pressures to ensure analysis of valve performance under higher standards. By analyzing the possible valve failure mechanism as indicated by the left ventricular endoscopy and implementing immediate measures to correct the problem, the chances of correcting technical causes of valve failures, which is a major prognostic indicator of long-term valve function, ${ }^{7,8}$ is greatly enhanced.

The excellent correlation with endoscopic and intraoperative TEE findings in this study is highly encouraging and adds conviction to the belief that seeing is indeed believing. The authors ${ }^{1}$ identify severe aortic regurgitation and make a decision regarding whether the repair is satisfactory. Nevertheless, the postprocedural leakage assessment is subjective in nature and lacks provisions to objectively quantify and discern the various degrees of aortic regurgitation. A 
systematic description to guide determination of the adequacy of valve function based on visual assessment of the endoscopic findings may be helpful in addressing these issues. As with all new procedures, a learning curve may be necessary to master this technique. Visualizing the valve may be difficult for various reasons, especially in regard to the time to set the position to ensure a clear field of view. Although the authors describe no major complications with this procedure, caution is warranted because manipulation of a collapsed heart may cause serious cardiac injury. Instrument selection seems to be a crucial factor as well and the authors, based on their experience, recommend using a flexible 8.5 Fr ureteroscope. The significance of this study lies in the potential to greatly boost surgeon confidence in regard to immediate repair outcomes, which in turn may significantly influence the type of surgery selected for young patients who stand to benefit most from a valvesparing root replacement procedure.

\section{References}

1. Miyahara S, Oka T, Takahashi H, Inoue T, Matsumori M, Tanaka H, et al Feasibility of intraoperative water testing in aortic valve repair: direct visualization from left ventricle with a videoscope. J Thorac Cardiovasc Surg. 2017; 154:24-9.

2. Okita Y, Oka T, Miyahara S, Okada K. Direct visualization of the aortic cusp from the left ventricle during aortic root reimplantation. J Thorac Cardiovasc Surg. 2012;144:981-2.

3. Tsagakis K, Benedik J, El Khoury G, Jakob H. Aortic valve repair: intraoperative evaluation of valve geometry by angioscopy. J Thorac Cardiovasc Surg. 2015;149: 1666-8.

4. Itoh T, Ohtsubo S, Furukawa K, Norita H. Aortic root endoscopy in valve sparing operations. J Thorac Cardiovasc Surg. 1997;114:141-2.

5. Furukawa K, Ohtsubo S, Itoh T. Aortic root endoscopy for aortic valve-sparing operations. J Thorac Cardiovasc Surg. 2016;152:638-9.

6. Boodhwani M, de Kerchove L, Watremez C, Glineur D, Vaovershelde JL, Norihomme P, et al. Assessment and repair of aortic valve cusp prolapse: implications for valve sparing procedures. J Thorac Cardiovasc Surg. 2011;141:917-25.

7. Oka T, Okita Y, Matsumori M, Okada K, Minami H, Munakata H, et al. Aortic regurgitation after valve-sparing aortic root replacement: modes of failure. Ann Thorac Surg. 2011;92:1639-44.

8. le Polain de Waroux JB, Pouleur AC, Robert A, Pasquet A, Gerber BL, Noirhomme $\mathrm{P}$, et al. Mechanisms of recurrent aortic regurgitation after aortic valve repair. JACC Cardiovasc Imaging. 2009;2:931-9. 